University of Nebraska - Lincoln

DigitalCommons@University of Nebraska - Lincoln

USDA National Wildlife Research Center - Staff Publications
U.S. Department of Agriculture: Animal and Plant Health Inspection Service

2012

\title{
Genetic evaluation of an attempted Rattus rattus eradication on Congo Cay, U.S. Virgin Islands, identifies importance of eradication units
}

\author{
Julie A. Savidge \\ Colorado State University - Fort Collins, julie.savidge@colostate.edu \\ Matthew W. Hopken \\ USDA/APHIS/WS National Wildlife Research Center
}

Gary W. Witmer

USDA-APHIS-Wildlife Services, gary.w.witmer@usda.gov

Susan M. Jojola

USDA/APHIS/WS National Wildlife Research Center, susan.jojola@aphis.usda.gov

Judy J. Pierce

Division of Fish and Wildlife

See next page for additional authors

Follow this and additional works at: https://digitalcommons.unl.edu/icwdm_usdanwrc

Savidge, Julie A.; Hopken, Matthew W.; Witmer, Gary W.; Jojola, Susan M.; Pierce, Judy J.; Burke, Patrick W.; and Piaggio, Antoinette J., "Genetic evaluation of an attempted Rattus rattus eradication on Congo Cay, U.S. Virgin Islands, identifies importance of eradication units" (2012). USDA National Wildlife Research Center - Staff Publications. 1190.

https://digitalcommons.unl.edu/icwdm_usdanwrc/1190

This Article is brought to you for free and open access by the U.S. Department of Agriculture: Animal and Plant Health Inspection Service at DigitalCommons@University of Nebraska - Lincoln. It has been accepted for inclusion in USDA National Wildlife Research Center - Staff Publications by an authorized administrator of DigitalCommons@University of Nebraska - Lincoln. 


\section{Authors}

Julie A. Savidge, Matthew W. Hopken, Gary W. Witmer, Susan M. Jojola, Judy J. Pierce, Patrick W. Burke, and Antoinette J. Piaggio 


\title{
Genetic evaluation of an attempted Rattus rattus eradication on Congo Cay, U.S. Virgin Islands, identifies importance of eradication units
}

\author{
Julie A. Savidge $\cdot$ Matthew W. Hopken • Gary W. Witmer • \\ Susan M. Jojola $\cdot$ Judy J. Pierce $\cdot$ Patrick W. Burke • \\ Antoinette J. Piaggio
}

This article is a U.S. government work, and is not subject to copyright in the United States.

Received: 9 October 2011/Accepted: 27 April 2012/Published online: 25 May 2012

(C) Springer Science+Business Media B.V. (outside the USA) 2012

\begin{abstract}
Congo Cay, U.S. Virgin Islands, has high value for breeding seabirds and is a potential reintroduction site for the endangered Virgin Islands tree boa (Epicrates monensis granti). However, introduced ship rats (Rattus rattus) undermine its conservation value. Three unsuccessful eradication attempts have been conducted since 1990, with the latest in 2006; rats were trapped 1.5 years later. We examined microsatellite DNA and mitochondrial DNA sequences of ship rats from Congo Cay and three other nearby cays to determine if rats found after the most recent eradication effort were surviving individuals or reinvaders from neighboring cays; we had no pre-eradication samples. Only one mitochondrial haplotype was present, implying that historically there was a single invasion or if multiple invasions, rats came
\end{abstract}

J. A. Savidge ( $\square)$

Department of Fish, Wildlife and Conservation Biology, Colorado State University, Fort Collins, CO 80523-1474, USA

e-mail: julie.savidge@ colostate.edu

M. W. Hopken · G. W. Witmer · S. M. Jojola ·

P. W. Burke · A. J. Piaggio

USDA/APHIS/WS National Wildlife Research Center, 4101 LaPorte Avenue, Fort Collins, CO 80521-2154, USA

J. J. Pierce

Division of Fish and Wildlife, 6291 Estate Nazareth,

St. Thomas, VI 00802, USA from a single source with limited haplotype diversity. Low genetic variation on Congo Cay suggested either a population bottleneck resulting from survivors or a founder event resulting from invaders. $F_{\mathrm{ST}}$ estimates, cluster distances, migrant detections, and factorial correspondence analysis indicated low but meaningful levels of gene flow between Congo and Lovango Cays and between Mingo and Grass Cays. Except for two alleles, all other alleles found on Congo were also present on Lovango. Without pre-eradication samples we could not eliminate the possibility of survivors from a failed eradication. However, our data suggest reinvasion from Lovango Cay was likely and that future eradication efforts should consider both pairs of cays as eradication units. Cay juxtaposition and orientation along with ocean currents may explain rat movement, or lack thereof, among these cays.

Keywords Eradication - Invasion - Island · Microsatellite $\cdot$ Rattus rattus $\cdot$ U.S. Virgin Islands

\section{Introduction}

Three species of rats (Norway rat, Rattus novegicus; ship rat, $R$. rattus; and the Pacific rat, $R$. exulans) have invaded over $80 \%$ of the world's oceanic island groups, frequently with devastating ecological results (Atkinson 1985). Rat eradication has become an important tool for recovery of insular endemic 
populations. As of a review by Howald et al. (2007), 332 successful rodent eradications had been undertaken globally, largely using toxicant baits distributed via bait stations, hand broadcasting, and aerial broadcasting. Although there have been many successful rat eradications (Veitch and Clout 2002; Donlan et al. 2003), such efforts sometimes fail (Courchamp et al. 2003; Clout and Russell 2006; Howald et al. 2007). Understanding reasons for failure is important for informing future efforts. If rats survive an eradication effort, then eradication methodologies should be reassessed. However, if rats reinvade an island, a larger area (eradication unit) should be targeted for control, for example, multiple islands, rather than the single island of concern (Robertson and Gemmell 2004; Abdelkrim et al. 2005a).

Population genetics can help determine colonization patterns. Consequently, recent studies have compared metrics of shared genetic diversity between rat populations before and after an eradication attempt, and between the post-eradication rat population and other potential source populations (another island or a mainland) to distinguish between failed eradication and reinvasion (e.g. Abdelkrim et al. 2005b, 2007; Russell et al. 2010). High levels of shared genetic diversity between pre- and post-eradication rat populations and low levels between a potential source population and the post-eradication population (suggesting limited connectivity) are evidence of a failed eradication (Robertson and Gemmell 2004; Abdelkrim et al. 2005a; Russell et al. 2010). Whereas, low levels of shared genetic diversity between the pre- and post-eradication populations and high levels between the post-eradication population and a potential source of rats suggest invasion following a successful eradication. However, if pre-eradication effort samples are not available, determining a failed eradication from an invasion can be challenging.

More than 50 small islands (cays) occur in the U.S. Virgin Islands (USVI; Dammann and Nellis 1992). Congo Cay is a relatively small cay about $2.2 \mathrm{~km}$ northwest of the island of St. John. This cay supports numerous seabirds and is important nesting habitat for brown pelicans (Pelecanus occidentalis) (Dewey and Nellis 1980; Dammann and Nellis 1992; Pierce 2009). In 1998, roseate terns (Sterna dougallii), the Caribbean population of which is federally listed as threatened (U.S. Fish and Wildlife Service 1987), nested on Congo Cay for the first time in recent history. However, after ship rats destroyed at least 75 eggs, all 273 nests were abandoned (J. J. Pierce, unpublished data). Furthermore, if rats could be removed, Congo Cay is thought desirable for reintroduction of the endangered Virgin Islands tree boa (Epicrates monensis granti), which would be an important conservation objective (U.S. Fish and Wildlife Service 2010). Between 1990 and 2006, resource management personnel from several agencies and organizations (U.S. Fish and Wildlife Service; USDA-Wildlife Services; USVI Department of Planning and Natural Resources; and The Toledo Zoo, USA) made three attempts to eradicate ship rats from Congo Cay. After the last eradication effort in 2006, rats were again detected 1.5 years later. Resource managers questioned whether rats had survived eradication efforts or were invaders from nearby cays. Invasive rats can reach islands via ships, storm flotsam, or by swimming (Russell et al. 2008). It is believed that ship rats swam $50 \mathrm{~m}$ to Goat Island, offshore from New Zealand's North Island, and swam $225 \mathrm{~m}$ to Pearl Island, offshore of Stewart Island, New Zealand (Russell et al. 2009, 2010). Therefore it is possible that rats reinvaded Congo Cay from nearby cays (Fig. 1).

Due to the importance of accomplishing successful eradication, our goal was to use rapidly evolving genetic markers to try and elucidate the origin of the rat population currently occupying Congo Cay. If rats reinvaded by swimming, Lovango Cay (230 m south and the most proximate cay to Congo Cay) was the likely source. We also wanted to aid and inform future eradication efforts on Congo Cay, and therefore we sampled two other nearby cays (Mingo and Grass) to help identify appropriate eradication units. Rats were not sampled on Congo Cay before the eradication effort, and to our knowledge, no published studies have attempted to detect the source of rat populations based solely on post-eradication DNA samples.

We used autosomal microsatellite loci to estimate genetic diversity and population differentiation within and among the cays, and mitochondrial DNA (mtDNA) control region sequences to obtain information on historical relationships among these cays. We hypothesized that the rat population on Congo Cay was either: (1) descendant from a remnant population remaining after a failed eradication (population bottleneck), or (2) a result of immigration from a nearby cay (founder event). We also acknowledged that both 
Fig. 1 Map showing trap lines and capture locations for $R$. rattus from four cays in the U.S. Virgin Islands

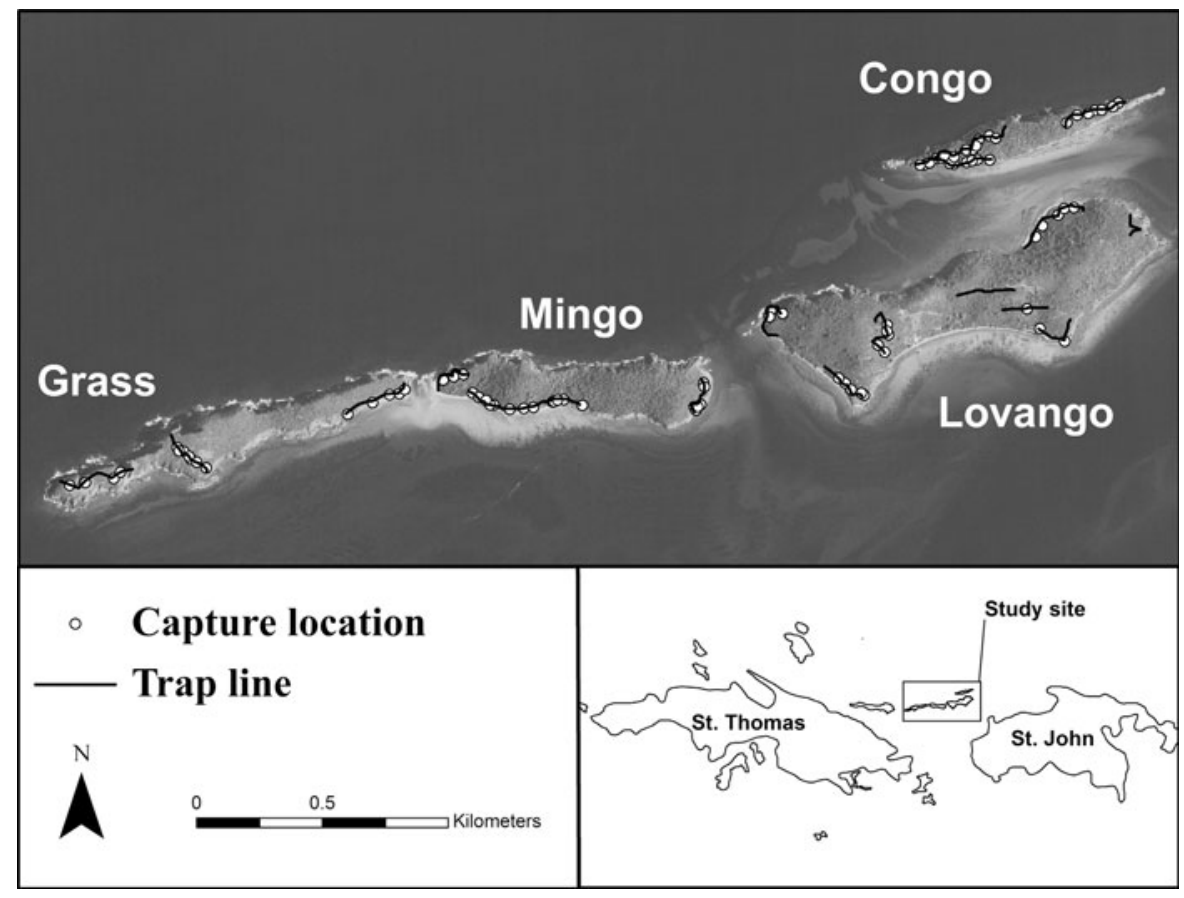

situations could have occurred (e.g. a combination of remnant individuals and reinvaders). We predicted that if the population originated from invaders, the allelic diversity of Congo Cay would be a subset of Lovango Cay. We used statistical approaches for studying population genetics to test this prediction.

\section{Materials and methods}

Study system

This study focused on the cays of Congo, Lovango, Mingo, and Grass in the USVI (Fig. 1). Congo Cay is the smallest of the four cays we sampled (10.6 ha). This uninhabited cay is owned by the USVI territorial government and is largely composed of rocks and boulders with a maximum elevation of approximately $51.5 \mathrm{~m}$ above sea level. Dry forest grows amongst the rocky substrate over most of the cay except the east and west ends, which taper to rocky points, and the north side, which is cliff. Like many of the small, government-owned islands in the USVI, Congo Cay is managed as a wildlife sanctuary and public use is discouraged (Pierce 2003). However, the channel between Congo and Lovango Cays is frequently used for snorkeling and diving activities. Lovango Cay, $230 \mathrm{~m}$ south of Congo Cay, is privately owned and the largest cay we sampled (47.7 ha). This cay also has the most boat traffic with two piers for docking. Mingo (19.6 ha) and Grass (19.7 ha) Cays are west of Lovango Cay. Shoal Passage, $260 \mathrm{~m}$ wide, separates Lovango and Mingo Cays; the passage between Mingo and Grass Cays is about $66 \mathrm{~m}$, but rock outcroppings serve as potential stepping-stones, with the widest stretch of water approximately $25 \mathrm{~m}$. Mingo Cay is privately owned and the USVI government owns Grass Cay. Strong tidal currents occur in the passes between each of the cays (D. W. Nellis, personal communication). Vegetation on all cays is classified as sub-tropical dry forest (Dammann and Nellis 1992).

\section{Eradication efforts on Congo Cay}

In 1990 and 1991, the USVI Department of Planning and Natural Resources, Division of Fish and Wildlife (DFW) and cooperators applied three rounds of brodifacoum rodenticide bait spaced 6 months apart over a $10 \times 10-\mathrm{m}$ grid covering Congo Cay. Ten blocks of bait were placed at each grid point and 
replenished as consumed (P. J. Tolson, The Toledo Zoo, personal communication). Because of difficult access in cliff areas, the team circled the cay by boat and used slingshots to shoot blocks into the more inaccessible areas. Rats were subsequently detected in 1993 on Congo Cay. In 2004, DFW and USDAWildlife Services attempted a second eradication. A grid of bait stations was used as well as handbroadcasting of diphacinone rodenticide bait blocks in cliff areas following a strategy that had proven successful on the 80-ha Buck Island off St. Croix, USVI (Witmer et al. 2007). Initial monitoring by DFW suggested rats had been removed, but in January 2006, 1.5 years post-eradication effort, rats were trapped on Congo (J. J. Pierce, unpublished data). As a rapid response measure, an emergency one-time use EPA registration for brodifacoum rodenticide bait was approved (Hall et al. 2006). Over three days in June 2006, USDA-Wildlife Services and DFW handbroadcast brodifacoum pellets over the entire cay with a target rate of $19.25 \mathrm{~kg} / \mathrm{ha}$. In the central, relatively flat part of the cay, a grid was established with points every $24.4 \mathrm{~m}$. Bait was applied at gridpoints at a rate of $300 \mathrm{~g}$ per point and $75 \mathrm{~g}$ were broadcast at each point in each cardinal direction. Bait was also applied at a rate of $600 \mathrm{~g}$ per point in each of the rocky points on the east and west ends of the cay. Additionally, bait was thrown at the base of the north shore cliff from a boat and into shoreline vegetation along the south shore by walking the shore (Hall et al. 2006). A total of $200.5 \mathrm{~kg}$ of bait was broadcast. A two-day trapping effort 6 months post-baiting failed to detect rats. In November 2007, approximately 1.5 years post-eradication effort, rats were again trapped on Congo (J. J. Pierce, unpublished data).

Field sampling

Pre-eradication samples were not obtained on Congo Cay. In June 2008, we set rat snap traps at approximately $20-\mathrm{m}$ intervals along non-random transects on each of the four cays (Fig. 1). Tail snips (1-2 cm) of captured rats were collected and samples preserved in a $20 \%$ dimethyl sulfoxide, $0.25 \mathrm{M}$ EDTA, saturated with $\mathrm{NaCl}, \mathrm{pH} 8.0$ solution (Seutin et al. 1991). We also received tissue from 18 rats collected on Congo Cay (one from November 2007 and 17 from February and March 2008) and three rats collected on Mingo Cay (two from November 2007 and one from February
2008) by DFW and USDA-Wildlife Services. Thus, our total sample included tissue from 58 rats from Congo Cay, 41 from Lovango Cay, 40 from Mingo Cay, and 24 from Grass Cay.

\section{DNA extraction and amplification}

Genomic DNA was extracted from tail snips using a DNeasy Tissue Extraction Kit (Qiagen Inc., Valencia, CA). We genotyped all samples $(n=163)$ from individual rats using ten autosomal microsatellite loci developed and characterized from $R$. norvegicus and R. fuscipes greyii (Jacob et al. 1995; Hinten et al. 2007, respectively; Table 1). Primers for amplifying these loci were fluorescently labeled on the $5^{\prime}$ end label with NED, FAM, or HEX. Further, to reduce problems with data interpretation caused by stutter and non-templated $3^{\prime}$ A nucleotide additions, both artifacts of polymerase chain reaction (PCR) amplification, we ordered each forward primer with a seven nucleotide "PIG-tail" (Brownstein et al. 1996). Genotypes were obtained through three panels we developed (Table 1) in 12.0-13.5 $\mu \mathrm{l}$ reactions (A, $12.0 \mu \mathrm{l}$; B, $13.5 \mu \mathrm{l}$; C, $12.5 \mu \mathrm{l}$ ) with $3.3 \mu \mathrm{l} 5 \times$ buffer $\mathrm{C}$ (Invitrogen, Carlsbad, CA), dNTPs (A, $1.2 \mathrm{mM}$; B, $1.35 \mathrm{mM}$; C, $1.25 \mathrm{mM}$; Invitrogen), $0.005 \mu \mathrm{g}$ bovine serum albumin (BSA), 0.033-0.13 $\mu \mathrm{M}$ primer, 1.0-1.5 U Taq DNA polymerase (GoTaq, Promega, Madison, WI; A and $\mathrm{C}, 1 \mathrm{U} ; \mathrm{B}, 1.5 \mathrm{U}), 1 \mu \mathrm{l}$ of genomic DNA and PCR water to total volume. PCR amplification consisted of an initial denaturation at $94{ }^{\circ} \mathrm{C}$ for $3 \mathrm{~min}$ followed by 45 cycles for panels $\mathrm{A}$ and $\mathrm{B}$ and 40 cycles for panel C of denaturing at $94{ }^{\circ} \mathrm{C}$ for $30 \mathrm{~s}$, annealing at $52{ }^{\circ} \mathrm{C}$ for $45 \mathrm{~s}$, and extension at $72{ }^{\circ} \mathrm{C}$ for $45 \mathrm{~s}$ with a final extension period of $30 \mathrm{~min}$ at $60{ }^{\circ} \mathrm{C}$. We mixed PCR products with HiDi Formamide (Applied Biosystems [ABI], Foster City, CA) and GeneScan 400HD ROX Size Standard (ABI). All fragments were visualized on an ABI 3130 genetic analyzer following standard protocols. Alleles were binned and we manually checked scoring using GENEMAPPER (ABI). We used the software packages GMCONVERT (Faircloth 2006) and CONVERT (Glaubitz 2004) to convert genotyping data to input formats for downstream statistical analyses.

Additionally, we sequenced the Hyper Variable Region I (HVRI) of the mitochondrial genome control region from 9 to 19 animals from each cay using primers L283 and H16498 (Anderson et al. 1981). The 
Table 1 Summary statistics for each locus and each population of $R$. rattus collected from four cays in the U.S. Virgin Islands

\begin{tabular}{|c|c|c|c|c|c|c|c|c|c|c|c|c|c|c|c|c|c|c|}
\hline \multirow[t]{2}{*}{ Panel } & \multirow[t]{2}{*}{ Locus } & \multirow[t]{2}{*}{ Range } & \multicolumn{4}{|c|}{ Congo } & \multicolumn{4}{|c|}{ Grass } & \multicolumn{4}{|c|}{ Lovango } & \multicolumn{4}{|c|}{ Mingo } \\
\hline & & & $N_{A}$ & $A_{R}$ & $H_{O}$ & $H_{E}$ & $N_{A}$ & $A_{R}$ & $H_{O}$ & $H_{E}$ & $N_{A}$ & $A_{R}$ & $H_{O}$ & $H_{E}$ & $N_{A}$ & $A_{R}$ & $H_{O}$ & $H_{E}$ \\
\hline A & D7Rat13 & 183-195 & 1 & 1.0 & - & - & 5 & 5.0 & 0.88 & 0.74 & 4 & 3.5 & 0.39 & 0.39 & 5 & 4.8 & 0.73 & 0.69 \\
\hline A & D10Rat20 & 104 & 1 & 1.0 & - & - & 1 & 1.0 & - & - & 1 & 1.0 & - & - & 1 & 1.0 & - & - \\
\hline A & RfgL3 & $261-263$ & 1 & 1.0 & - & - & 2 & 2.0 & 0.04 & 0.04 & 1 & 1.0 & - & - & 1 & 1.0 & - & - \\
\hline B & D9Rat13 & $132-138$ & 1 & 1.0 & - & - & 2 & 2.0 & 0.46 & 0.39 & 2 & 2.0 & 0.34 & 0.28 & 3 & 3.0 & 0.75 & 0.65 \\
\hline B & D11Mgh5 & 284-294 & 4 & 3.4 & 0.47 & 0.43 & 4 & 4.0 & 0.63 & 0.65 & 3 & 3.0 & 0.61 & 0.62 & 5 & 4.9 & 0.68 & 0.66 \\
\hline B & D11Rat56 & 193 & 1 & 1.0 & - & - & 1 & 1.0 & - & - & 1 & 1.0 & - & - & 1 & 1.0 & - & - \\
\hline B & D18Rat75 & 185-189 & 2 & 2.0 & 0.43 & 0.38 & 2 & 2.0 & 0.63 & 0.50 & 2 & 2.0 & 0.51 & 0.48 & 3 & 2.8 & 0.33 & 0.47 \\
\hline $\mathrm{C}$ & D5Rat83 & $178-180$ & 2 & 2.0 & 0.40 & 0.36 & 2 & 2.0 & 0.25 & 0.22 & 2 & 2.0 & 0.15 & 0.18 & 2 & 2.0 & 0.18 & 0.16 \\
\hline $\mathrm{C}$ & D16Rat81 & $172-174$ & 1 & 1.0 & - & - & 2 & 2.0 & 0.25 & 0.22 & 2 & 1.8 & 0.05 & 0.05 & 2 & 2.0 & 0.30 & 0.32 \\
\hline \multirow[t]{2}{*}{$\mathrm{C}$} & RfgG3 & $229-257$ & 5 & 4.4 & 0.74 & 0.72 & 4 & 4.0 & 0.50 & 0.62 & 6 & 5.9 & 0.63 & 0.64 & 7 & 6.1 & 0.58 & 0.53 \\
\hline & Mean & & 1.9 & 1.8 & 0.20 & 0.19 & 2.5 & 2.5 & 0.36 & 0.34 & 2.4 & 2.3 & 0.27 & 0.26 & 3.0 & 2.9 & 0.35 & 0.35 \\
\hline
\end{tabular}

Panel represents one of three multiplex reactions. Range is the size range in base pairs of each locus. $N_{A}$ is the total number of alleles for each locus. $A_{R}$ is the allelic richness accounting for differences in sample sizes. $H_{O}$ and $H_{E}$ represent observed and expected heterozygosities, respectively. A dash (-) represents monomorphic loci. Loci are from Jacob et al. (1995) and Hinten et al. (2007)

PCR was run in $20-\mu \mathrm{l}$ reactions that contained $12 \mu \mathrm{l}$ PCR water, $3.6 \mu \mathrm{l} 5 \times$ buffer C (Invitrogen), $0.5 \mathrm{mM}$ dNTP (Invitrogen), $0.5 \mu \mathrm{M}$ of each primer, $1 \mathrm{U} \mathrm{Taq}$ DNA polymerase (Promega), and $1.0 \mu \mathrm{l}$ of genomic DNA. Thermocycling was at $94{ }^{\circ} \mathrm{C}$ for $4 \mathrm{~min}$ followed by 34 cycles of denaturing at $94{ }^{\circ} \mathrm{C}$ for $45 \mathrm{~s}$, annealing at $52{ }^{\circ} \mathrm{C}$ for $45 \mathrm{~s}$, and extension at $72{ }^{\circ} \mathrm{C}$ for 1 min with a final extension period of $5 \mathrm{~min}$ at $72{ }^{\circ} \mathrm{C}$. We purified successful amplifications using ExoSAPIT (USB, Cleveland, OH). Sequencing reactions were performed with $1.0 \mu \mathrm{l}$ of purified PCR product, $1.0 \mu \mathrm{M}$ primer and BigDye version $3.1 \mathrm{kit}(\mathrm{ABI})$ reagents and adapting the standard protocol to $1 / 4$ reactions. Sequences were visualized on an ABI 3130xl genetic analyzer using manufacturer recommended settings. We edited and aligned sequences in Sequencher (version 4.9, Gene Codes Corporation, Ann Arbor, MI). Sequencing was conducted at USDA/ APHIS/WS National Wildlife Research Center, Wildlife Genetics Laboratory.

\section{Genetic analyses}

We tested for the presence of null alleles (i.e. alleles that do not amplify) using MICRO-CHECKER (Van Oosterhout et al. 2004) with 9000 Monte Carlo simulations and $90 \%$ confidence intervals. Loci were examined for significant departures from HardyWeinberg equilibrium and significant evidence of linkage disequilibria using ARLEQUIN 3.1 (Excoffier et al. 2005). Bonferroni corrections were applied to compute critical significance levels for multiple tests (Rice 1989).

Standard measures of genetic diversity including mean number of alleles $\left(N_{A}\right)$, mean allelic richness $\left(A_{R}\right)$ adjusted for differences in sample size, number of private alleles per locus, and observed and expected heterozygosity ( $H_{O}$ and $H_{E}$, respectively) were estimated using FSTAT 2.9.3.2 (Goudet 2001) and ARLEQUIN 3.1. We tested for significant differences in genetic diversity measures, $N_{A}, A_{R}$ and $H_{E}$, among the cays using a Mann-Whitney $U$-test (Sokal and Rohlf 1981).

We estimated pairwise comparisons of genetic differentiation between rat populations on the cays ( $F_{\mathrm{ST}}$; Weir and Cockerham 1984). Significance of the comparisons was ascertained by producing an expected distribution based on randomizations generated with 9000 Monte Carlo simulations. We used Mantel tests to determine statistical significance of an isolation-by-distance test by comparing linearized $F_{\text {ST }}$ (Slatkin 1993) and the Euclidean (straight-line) distance in kilometers. These analyses were conducted in ARLEQUIN 3.1. Euclidean distances were calculated as shortest distances for a swimming rat from cay to cay and from the centroid of each cay.

The software BAPS 5.2 (Bayesian Analysis of Population Structure; Corander et al. 2004; Corander et al. 2008) was used to estimate the number of populations or clusters $(K)$, genetic distance between clusters, and levels of admixture. BAPS uses a stochastic 
optimization algorithm to estimate the most likely number of clusters. First we performed the clustering analysis based on individual genotypes ignoring sampling information (non-spatial model) and second, based on groups of individual genotypes with each cay considered a group, and finally we used clustering of individuals with sampling location (cay) as a prior (spatial model). These alternate approaches were used to test if each cay represented a single genetic cluster. Nei's genetic distance $(D)$ was estimated between identified clusters (Nei 1972). Our analyses were conducted with $K=1-15$, with each value replicated five times; we chose an upper limit of 15 as we felt this was a reasonable maximum number of clusters to expect in this system. The analyses were run 10 times, and we present the highest resulting likelihood score. We then used the results from the group clustering analysis to perform admixture analysis among cays with each cay being considered a population. We used 100 iterations to estimate the admixture coefficients for the individuals. Following the procedure described by Corander and Marttinen (2006), we assessed the probability that these admixture coefficients could have arisen by chance alone by simulating 200 nonadmixed reference individuals from each population and running 50 iterations each to estimate their admixture coefficients.

To test for first-generation migrants (i.e. individuals from a population other than the one in which they were sampled), we used GENECLAss2 (Piry et al. 2004) with a Bayesian (Rannala and Mountain 1997) statistical criterion of likelihood estimation set to the ratio of the likelihood of the genotype occurring within the sampled population to the highest likelihood of that genotype having come from another sampled population (Paetkau et al. 2004). Significance was determined using the Monte Carlo resampling method with the simulation algorithm of Paetkau et al. (2004) for 10,000 individuals and an $\alpha=0.01$. The two loci fixed in all populations (see "Results") were excluded from this analysis.

We used a factorial correspondence analysis (FCA) implemented in GENETIX version 4.05.2 to further test genetic clustering (Belkhir et al. 1996-2004). FCA is a multivariate ordination technique that allows visualization of allelic diversity/frequencies clustering in three-dimensional space. FCA differs from the Bayesian clustering methods in that it is model-free and thus avoids any prior assumptions about the nature and relationships of the data.

Lastly, we examined mitochondrial DNA diversity to infer whether the four cays were colonized by multiple maternal lineages. The GenBank accession numbers are GU269243-GU269246. Haplotypes obtained from the cays were compared to other HVRI $R$. rattus sequences publicly available through GenBank via BLAST searches to determine if there was any geographical correlation of haplotypes from these cays to other proximate islands or landmasses.

\section{Results}

We found no evidence of null alleles at any locus. Three linkage disequilibrium tests were significant in the Mingo Cay population, however five would be expected by chance at $\alpha=0.05$. Therefore, based on Bonferroni corrections we considered all loci independent. There were no significant deviations from Hardy-Weinberg equilibrium per locus or cay $(P<0.01)$.

The mean number of alleles per population across loci ranged from 1.9 (Congo Cay) to 3.0 (Mingo Cay) (Table 1). Mean allelic richness was similar to the mean number of alleles, ranging from 1.8 (Congo Cay) to 2.9 (Mingo Cay). Observed heterozygosity was lowest on Congo Cay (0.20). Although Congo Cay had the lowest genetic diversity among the cays, the differences in mean number of alleles, allelic richness, and expected heterozygosity were not statistically significant among cays (Mann-Whitney $U$-test; $P>0.05)$. There was one private allele each for Congo Cay and Lovango Cay, two on Grass Cay, and five on Mingo Cay. The private allele on Congo Cay was from a single individual, and to eliminate the possibility of scoring error generated from PCR artifacts, we replicated the PCR three more times for this individual. Two loci were monomorphic or fixed (D10Rat20 and D11Rat56) in all populations. Besides these two loci, Congo, Lovango, and Mingo Cays shared a third fixed locus (RfgL3). In addition, Congo Cay had three other fixed loci (D7Rat13, D9Rat13, and D16Rat81; for a total of six fixed loci out of ten; Table 1). Figure 2 shows allelic diversity shared between Lovango and Congo Cays and demonstrates the level of fixation and possible loss of rare alleles on Congo. Three of eight alleles that were rare $(<10 \%$ 


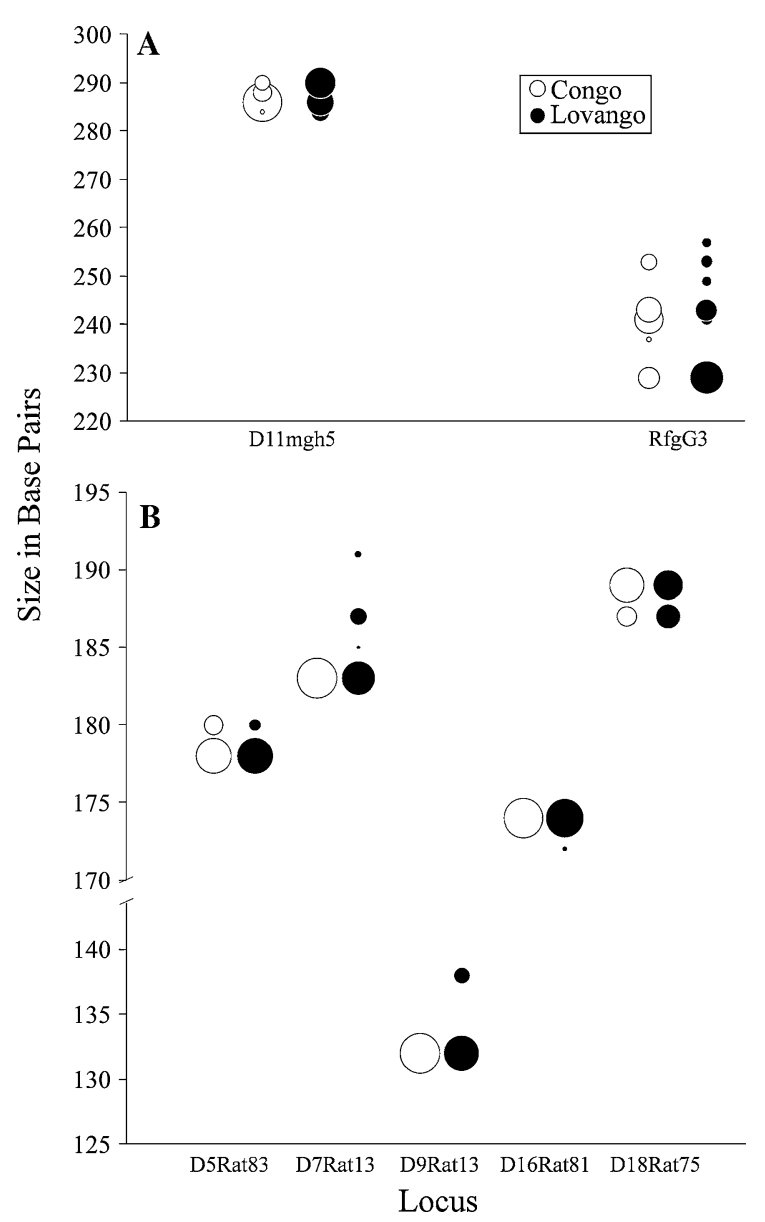

Fig. 2 Bubble plot of allele frequencies of $R$. rattus samples collected from Congo and Lovango Cays in the U.S. Virgin Islands. Only loci that were polymorphic in at least one population are graphed $(n=7)$. Each bubble represents one allele and the size of the bubble represents the frequency. Plot A presents polymorphic loci over $200 \mathrm{bp}$ in length and plot B presents polymorphic loci under $200 \mathrm{bp}$

frequency) on Lovango also occurred on Congo. Congo Cay shared an allele at locus D11mgh5 with Mingo, but the allele was not detected on either Lovango or Grass Cays.

All pairwise $F_{\mathrm{ST}}$ estimates between the cays were significant $(P<0.01)$. However, pairwise genetic differentiation was lower between Grass and Mingo Cays (0.08) and Congo and Lovango Cays (0.14). It ranged from 0.32 to 0.44 between all other pairwise comparisons (Table 2). Isolation-by-distance tests with the two different geographic distance measures were not significant.

The individual clustering analysis ignoring sampling locality information in BAPS identified $K=11$
Table $2 F_{\mathrm{ST}}$ values for $R$. rattus samples from four cays in the U.S. Virgin Islands

\begin{tabular}{lllll}
\hline & Congo & Grass & Lovango & Mingo \\
\hline Congo & - & & & \\
Grass & 0.44 & - & & \\
Lovango & 0.14 & 0.32 & - & - \\
Mingo & 0.41 & 0.08 & 0.33 & - \\
\hline
\end{tabular}

All values are significantly different from zero $(P<0.01)$

$(-\ln$ likelihood $=1666.9302)$ clusters; most clusters were unique to each cay and shared clusters were either between Lovango and Congo Cays or Grass and Mingo Cays. The 11 clusters could reflect more closely related individuals, which our sampling approach may have tended to capture. The group clustering analysis of individuals identified $K=4$ $(-\ln$ likelihood $=1732.9026)$, corresponding to each of the four cays. When geographic locality information for each individual was included, the individual analysis also found $K=4$ clusters ( - ln likelihood $=1802.9040$ ), which generally correlated to the four cays. However, three individuals captured on Congo Cay clustered with the Lovango cluster, a single individual captured on Grass Cay belonged to the Mingo cluster, and an individual captured on Mingo Cay assigned to the Grass cluster. Nei distances estimated from the clustering of groups of individuals showed lower distances between Congo and Lovango (0.390) and Mingo and Grass (0.347) than Lovango to Mingo or Grass (0.838 and 0.963 , respectively) and Congo to Grass or Mingo (1.467 and 1.624, respectively). The admixture analysis identified a single individual from Congo Cay in the Lovango Cay cluster. Three first-generation migrants were detected in the GENECLASS analysis. Two were between Lovango Cay and Congo Cay and the final was from Grass Cay to Mingo Cay.

The FCA factor values of the first two axes totaled $26.17 \%$ (Fig. 3: axis $1=18.38 \%$; axis $2=$ $7.79 \%)$. All remaining axes had individual factor values of $<7 \%$ with minimal spread on the graph. Thus, we concluded that only axes 1 and 2 provided information regarding relationships. Axis 1 represented the most important spread of the data, which aligned samples mostly by geography (cays). However, regions of overlap existed between Congo and Lovango Cays and between Grass and Mingo Cays. In 


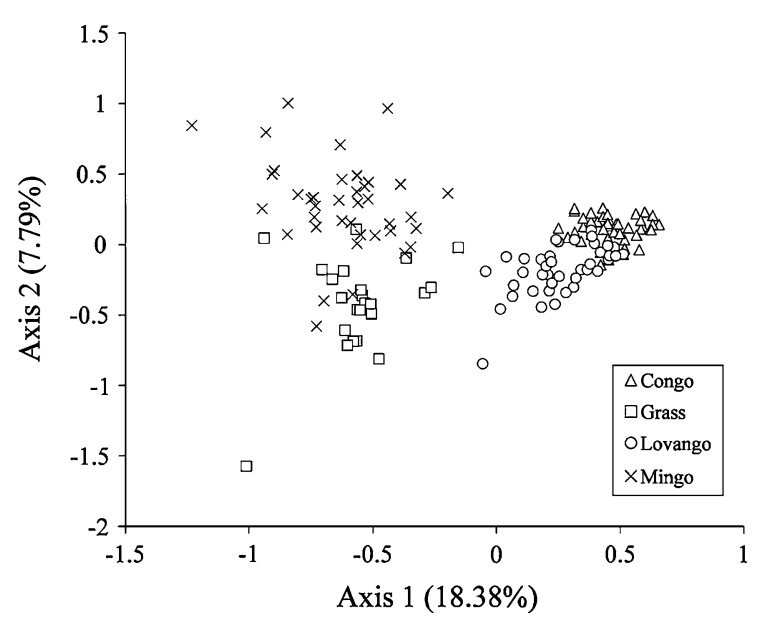

Fig. 3 Scatter plot of the results from the factorial correspondence analysis (FCA) of $R$. rattus genotypes sampled from four cays in the U.S. Virgin Islands. Axes 1 and 2 were graphed and labeled with associated factor values

fact, Grass and Mingo Cays were nearly indistinguishable on axis 1 with most separation on axis 2, whereas Lovango and Congo Cays had almost equal amounts of overlap and separation. Congo Cay had a much tighter clustering pattern on both axes than the other three cays, suggesting less variability among the data points within this sample.

DNA sequencing of the HVRI region provided 508 bp of sequence data. Although this is a region of the mitochondria that is hypervariable, we found only one haplotype in all 54 individuals sequenced from all four cays. When this single haplotype was compared to sequences available on NCBI GenBank, the greatest similarity (98\% match) was to a haplotype from Guadeloupe Island in the Lesser Antilles (FJ897500; Prugnolle et al. 2005), which is approximately $402 \mathrm{~km}$ from USVI. Also, other researchers found the Guadeloupe haplotype (FJ897499; unpublished) on the African continent in Senegal.

\section{Discussion}

We tested two hypotheses: (1) the rat population on Congo Cay was descendant of a remnant population remaining after a failed eradication (population bottleneck), and (2) the rat population on Congo Cay was a result of immigration from a nearby cay (founder event). Our genetic data indicated a recent reduction of the rat population on Congo Cay. Congo Cay had the lowest genetic diversity of the four cays investigated, the highest number of fixed loci, and only three alleles that were present in low frequency on Lovango Cay (other alleles on Congo Cay were either private $(n=1)$, common $(>10 \%$ frequency) on Lovango Cay, or in the case of one allele, found on Mingo but not Lovango). Thus, we detected evidence of either a bottleneck or founder event on Congo Cay and theory predicts that it is not possible to differentiate the two (Hedrick 2005). Because we lacked pre-eradication samples, we took several approaches to analyzing our genetic data to see if these would together lend a weight of evidence to either hypothesis.

We found significant differentiation among the cays. However, the pairwise $F_{\mathrm{ST}}$ estimates, cluster distances, migrant detections, and FCA indicate low levels of gene flow between Lovango and Congo Cays and between Grass and Mingo Cays, but very little if any occurs between the other pairs of cays. Additionally, visual examination of allele frequencies suggests allelic diversity on Congo Cay could be a subset of that on Lovango. Except for two alleles (one of which was private), all other alleles found on Congo were also present on Lovango. The presence of private alleles (i.e. alleles found on only one cay) can be indicative of limited gene flow and evidence in support of a failed eradication. However, our finding of only one private allele on Congo Cay was not remarkable. The allele occurred at low frequency (0.009) and could have been a sampling artifact. Our analyses suggest the shared allele between Congo and Mingo Cays represents a historic migration event and shared common ancestry, rather than recent immigration directly from Mingo Cay. Thus based on our results, we suggest that the rat population on Congo Cay is at least in part a result of rat immigration from Lovango after the eradication attempts. Additionally, the failure of three eradication efforts involving experienced personnel using techniques that had been successful on other cays in the USVI (Witmer et al. 2011), also suggests recolonization occurred. However, even though we found no strong support, we are unable to reject the alternative hypothesis that at least some rats also survived the eradication event.

The mtDNA HVRI was used to reconstruct invasion history of ship rats in the southern tip of the island of Madagascar (Hingston et al. 2005) where thirteen haplotypes were detected. In our examination of samples from Congo, Lovango, Grass, and Mingo 
Cays, we only identified a single haplotype. This suggests that either there was a single invasion from one source population or there have been multiple introductions from a single source where there is limited haplotype diversity. Because our sampling was restricted to our four cays and the available HVRI sequences from the Caribbean and Africa are not wellrepresented in GenBank, we can not pinpoint the origin of rats in our study area, however a possible route is from Africa via the slave trade, which was active in the USVI during the 1700's and up until the early 1800's (Rawley and Behrendt 2005).

We did not find a pattern of isolation-by-distance. Presumably several factors influence a rat's ability to traverse sea channels and invade an island. A study by Abdelkrim et al. (2009) in the Lavezzi Mediterranean archipelago concluded that ship rats likely swam between the main island of Lavezzu and surrounding islets (in general, distances of $<200 \mathrm{~m}$ ), and two studies in New Zealand by Russell et al. (2009, 2010) concluded ship rats swam distances of 50 and $225 \mathrm{~m}$ to reinvade islands. However, Calmet et al. (2001) found that in the Molene archipelago, Norway rats on islands separated by permanent channels $(>2 \mathrm{~km})$ were genetically differentiated, and these authors suggested sea channels are important barriers to gene flow. Based on our results it appears that the channel between Mingo and Lovango Cays is an important barrier to gene flow, whereas the channel between Lovango and Congo Cays only serves to limit gene flow, not stop it. Although a rat could have invaded from a boat utilizing the channel between Congo and Lovango Cays, our allelic diversity results suggest it is unlikely that the current rat population on Congo established from an invader outside our system. It is unlikely that humans would accidentally transport rats directly to Congo; the public is not allowed on the cay because of its conservation value to seabirds. Furthermore, the entire coastline is comprised of boulders and cliffs, and there are no beaches or docks. We believe the main pathway for rat colonization of Congo Cay is via swimming the channel between Congo and Lovango Cays.

Juxtaposition and orientation of the cays might help explain potential rat movement (or lack thereof) among the four cays. All three channels between the cays have strong ocean currents. However, Congo Cay is north of Lovango Cay (Fig. 1) and if a rat was to attempt to cross the channel from Lovango to Congo
Cay or vice versa, it has a reasonable chance of intercepting shoreline because the long axes of both cays are parallel (Fig. 1). Grass, Mingo, and Lovango Cays, because of their east-west orientation to each other, have relatively little opposing shoreline. With strong currents, a rat should have less chance of intercepting shoreline of one of these cays if attempting to cross from one to the other. The larger distance between Lovango and Mingo Cays (260 m) might make this particularly challenging compared with the shorter distance between Mingo and Grass Cays (a minimum swim of about $25 \mathrm{~m}$ if the rock outcroppings were used) and between Lovango and Congo Cays. This hypothesis is consistent with island biogeography theory and the concepts of distance and target effect influencing immigration (MacArthur and Wilson 1963, 1967; Lomolino 1990). Indeed, Buckley and Knedlhans (1986) found that islands with longer beaches had a greater sample of seaborne plant propagule species. One might predict even less differentiation than we found between Mingo and Grass Cays, based on distance. Either our sampling was inadequate to capture the full genetic diversity on Grass Cay or the strong current between the two cays presents a substantial challenge to migrating rats.

Our results suggest low levels of gene flow between Lovango and Congo Cays and between Grass and Mingo Cays. Therefore each pair should be considered an eradication unit and any further eradication attempts on Congo Cay should include rat eradication on Lovango Cay, or at least sustained, intensive control efforts along the shore opposing Congo Cay. The five private microsatellite alleles on Mingo are a signal that Mingo may have been the original invasion point for rats among these four cays. Thus, a prudent approach also would be eradication of rats on Mingo and Grass. Furthermore, if further efforts were considered, rats should be sampled on Thatch Cay (west of Grass Cay) and the larger islands of St. Thomas and St. John to try and ascertain the likelihood of immigration from any of these islands.

Biologists are increasingly using genetic approaches to evaluate various aspects of biological invasions (Rollins et al. 2006; Roux and Wieczorek 2009). Information on potential metapopulation dynamics for an invasive species, which genetic analyses can provide, is important for successful eradication. To robustly test for cause of eradication failure should that occur, genetic samples collected prior to eradication 
attempts can help shed light on the cause for failure (Abdelkrim et al. 2005a, 2007). However, several papers have cautioned about the potential limitations of genetic analyses (e.g. Manel et al. 2005; Chikhi et al. 2010; Fitzpatrick et al. 2012). For instance, inferences based on genetic methods that assume equilibrium conditions (e.g. Wright's $F$-statistics), may not be valid as these conditions may require long timescales. Furthermore, if there is gene flow and populations are not sufficiently genetically differentiated, it becomes increasingly difficult to match individuals to their source population (Manel et al. 2005; Muirhead et al. 2008; Fitzpatrick et al. 2012). Thus, in our system, where we appeared to have low but ongoing gene flow between Lovango and Congo and low levels of polymorphism, even if we had pre-eradication samples, it may have been difficult to distinguish between the two hypotheses of a failed eradication versus recolonization.

Because eradication campaigns are expensive, we recommend an initial genetic survey before the eradication effort to conservatively estimate the scale and complexity of differentiation of the target population, indentify genetic barriers, and help support or refute independent hypotheses about connectivity. In our island system, an initial survey may have revealed the scale of eradication needed by asserting that eradication units existed. Managers should be particularly cautious in attempting eradications on islands that are within known movement capabilities of the target species (Harris et al. 2011). At the least, preeradication samples should be collected as these have been shown useful in evaluating reasons for eradication failure if adequate structure exists among populations. In lieu of pre-eradication samples, a combination of genetic analyses may be able to elucidate important processes, which could still be useful for informing future eradication efforts.

Acknowledgments We sincerely thank C. Colletti, D. Nellis, and T. Seibert for helping collect rat samples; J. Figueroa and M. Neubaum for help with laboratory procedures; F. Boyd of USDA-Wildlife Services for contributing rat samples from Congo and Lovango Cays; and P. Tolson, S. Vessey, and D. W. Nellis for information on the first eradication attempt on Congo. We are grateful to J. B. Morissette, D. Boyd, J. DeCorsi, and W. Leopold for allowing access to their land on Lovango Cay and J. Markus, M. Brown and staff for setting traps and collecting data on the Markus property. M. R. Douglas provided input on experimental design. Special thanks to T. Seibert, J. Russell, C. Richards, and M. Antolin for thoughtful discussion on interpretation of various results. Two anonymous reviewers provided valuable comments. Funding was provided by USDA/ APHIS/WS National Wildlife Research Center and a grant from the Warner College of Natural Resources, Colorado State University. USFWS Region 4 Wildlife Restoration Grant W23 provided funding for J. Pierce. Research was conducted under Colorado State University ACUC protocol no. 08-107A-02.

\section{References}

Abdelkrim J, Pascal M, Calmet C, Samadi S (2005a) Importance of assessing population genetic structure before eradication of invasive species: examples from insular Norway rat populations. Conserv Biol 19:1509-1518

Abdelkrim J, Pascal M, Samadi S (2005b) Island colonization and founder effects: the invasion of the Guadeloupe islands by ship rats (Rattus rattus). Mol Ecol 14:2923-2931

Abdelkrim J, Pascal M, Samadi S (2007) Establishing causes of eradication failure based on genetics: case study of ship rat eradication in Ste. Anne archipelago. Conserv Biol 21:719-730

Abdelkrim J, Pascal M, Samadi S (2009) Genetic structure and functioning of alien ship rat populations from a Corsican micro-insular complex. Biol Invasions 11:473-482

Anderson S, Bankier AT, Barrell BG et al (1981) Sequence and organization of the human mitochondrial genome. Nature 290:457-465

Atkinson IAE (1985) The spread of commensal species of Rattus to oceanic islands and their effects on island avifaunas. In: Moors PJ (ed) Conservation of island birds. International Council for Bird Preservation Technical Publication No. 3, Cambridge, pp 35-81

Belkhir K, Borsa P, Chikhi L, Raufaste N, Bonhomme F (1996-2004) GENETIX 4.05: logiciel sous windows TM pour la génétique des populations. Laboratoire Génome, Populations, Interactions, CNRS UMR 5000, Université de Montpellier II, Montpellier, France. http://www.genetix.univmontp2.fr/genetix/genetix.htm

Brownstein MJ, Carpten JD, Smith JR (1996) Modulation of non-templated nucleotide addition by tag DNA polymerase: primer modifications that facilitate genotyping. Biotechniques 20:1004-1010

Buckley RC, Knedlhans SB (1986) Beachcomber biogeography: interception of dispersing propagules by islands. J Biogeogr 13:69-70

Calmet C, Pascal M, Samadi S (2001) Is it worth eradicating the invasive pest Rattus norvegicus from Molene archipelago? Genetic structure as a decision-making tool. Biodivers Conserv 10:911-928

Chikhi L, Sousa VC, Luisi P, Goossens B, Beaumont MA (2010) The confounding effects of population structure, genetic diversity and the sampling scheme on the detection and quantification of population size changes. Genetics 186:983-995

Clout MN, Russell JC (2006) The eradication of mammals from New Zealand islands. In: Koike F, Clout MN, Kawamichi M, De Poorter M, Iwatsuki K (eds) Assessment and control of biological invasion risks. IUCN, Gland, Switzerland and Cambridge, UK and Shoukadoh Book Sellers, Kyoto, pp 127-141 
Corander J, Marttinen P (2006) Bayesian identification of admixture events using multilocus molecular markers. Mol Ecol 15:2833-2843

Corander J, Waldmann P, Marttinen P, Sillanpaa MJ (2004) BAPS 2: enhanced possibilities for the analysis of genetic population structure. Bioinformatics 20:2363-2369

Corander J, Marttinen P, Siren J, Tang J (2008) Enhanced Bayesian modelling in BAPS software for learning genetic structures of populations. BMC Bioinformatics 9:539

Courchamp F, Chapuis JL, Pascal M (2003) Mammal invaders on islands: impact, control and control impact. Biol Rev 78:347-383

Dammann AE, Nellis DW (1992) A natural history atlas to the cays of the U.S. Virgin Islands. Pineapple Press, Inc., Sarasota

Dewey RA, Nellis DW (1980) Seabird research in the U.S. Virgin Islands. Trans N Am Wildl Conf 45:445-452

Donlan CJ, Tershy BR, Campbell K, Cruz F (2003) Research for requiems: the need for more collaborative action in eradication of invasive species. Conserv Biol 17:1850-1851

Excoffier L, Laval G, Schneider S (2005) Arlequin (version 3.0): an integrated software package for population genetics data analysis. Evol Bioinformatics 1:47-50

Faircloth BC (2006) GMCONVERT: file conversion for genemapper output files. Mol Ecol Notes 6:968-970

Fitzpatrick BM, Fordyce JA, Niemiller ML, Reynolds RG (2012) What can DNA tell us about biological invasions? Biol Invasions 14:245-253

Glaubitz JC (2004) CONVERT: a user-friendly program to reformat diploid genotypic data for commonly used population genetic software packages. Mol Ecol Notes 4:309-310

Goudet J (2001) FSTAT (version 2.9.3): a program to estimate and test gene diversities and fixation indices (updated from Goudet 1995). http://www.unil.ch/izea/softwares.fstat.html

Hall P, Eisemann J, Steen F, Witmer G, Boyd F (2006) Roof rat (Rattus rattus) eradication report: Congo Cay, U.S. Virgin Islands. USDA-Wildlife Services, Auburn

Harris DB, Gregory SD, Bull LS, Courchamp F (2011) Island prioritization for invasive rodent eradications with an emphasis on reinvasion risk. Biol Invasions. doi: 10.1007/s10530-011-0153-1

Hedrick PW (2005) Genetics of populations. Jones and Bartlett, Boston

Hingston M, Goodman SM, Ganzhorn JU, Sommer S (2005) Reconstruction of the colonization of southern Madagascar by introduced Rattus rattus. J Biogeogr 32:1549-1559

Hinten GN, Rossetto M, Baverstock PR (2007) New microsatellite markers for the bush rat, Rattus fuscipes greyii: characterization and cross-species amplification. Mol Ecol Notes 7:1254-1257

Howald G, Donlan CJ, Galvan JP et al (2007) Invasive rodent eradication on islands. Conserv Biol 21:1258-1268

Jacob HJ, Brown DM, Bunker RK et al (1995) A genetic linkage map of the laboratory rat, Rattus norvegicus. Nat Genet 9:63-69

Lomolino MV (1990) The target area hypothesis - the influence of island area on immigration rates of non-volant mammals. Oikos 57:297-300
MacArthur RH, Wilson EO (1963) Equilibrium theory of insular zoogeography. Evolution 17:373-387

MacArthur RH, Wilson EO (1967) The theory of island biogeography. Princeton University Press, Princeton

Manel S, Gaggiotti OE, Waples RS (2005) Assignment methods: matching biological questions with appropriate techniques. Trends Ecol Evol 20:136-142

Muirhead JR, Gray DK, Kelly DW, Ellis SM, Heath DD, Macisaac HJ (2008) Identifying the source of species invasions: sampling intensity vs. genetic diversity. Mol Ecol 17:1020-1035

Nei M (1972) Genetic distance between populations. Am Nat 106:283-292

Paetkau D, Slade R, Burden M, Estoup A (2004) Genetic assignment methods for the direct, real-time estimation of migration rate: a simulation-based exploration of accuracy and power. Mol Ecol 13:55-65

Pierce J (2003) Eradication of non-native rats from Virgin Islands offshore cays. Final Environmental Assessment. USVI Department of Planning and Natural Resources, Division of Fish and Wildlife, St. Thomas

Pierce J (2009) United States Virgin Islands. In: Bradley PE, Norton RL (eds) An inventory of breeding seabirds of the Caribbean. University Press of Florida, Gainsville, pp 99-111

Piry S, Alapetite A, Cornuet JM, Paetkau D, Baudouin L, Estoup A, Kumar S (2004) GENECLASS2: a software for genetic assignment and first-generation migrant detection. J Hered 95:536-539

Prugnolle F, Theron A, Pointier JP, Jabbour-Zahab R, Jarne P, Durand P, De Meeus T (2005) Dispersal in a parasitic worm and its two hosts: consequence for local adaptation. Evolution 59:296-303

Rannala B, Mountain JL (1997) Detecting immigration by using multilocus genotypes. Proc Natl Acad Sci USA 94:9197-9201

Rawley JA, Behrendt SD (2005) The transatlantic slave trade: a history. University of Nebraska Press, Lincoln

Rice WR (1989) Analyzing tables of statistical tests. Evolution 43:223-225

Robertson BC, Gemmell NJ (2004) Defining eradication units to control invasive pests. J Appl Ecol 41:1042-1048

Rollins LA, Woolnough AP, Sherwin WB (2006) Population genetic tools for pest management: a review. Wildl Res 33:251-261

Roux JL, Wieczorek AM (2009) Molecular systematics and population genetics of biological invasions: towards a better understanding of invasive species management. Ann Appl Biol 154:1-17

Russell JC, Towns DR, Clout MN (2008) Review of rat invasion biology: implications for island biosecurity. Science for Conservation 286. New Zealand Department of Conservation, Wellington

Russell JC, Mackay JWB, Abdelkrim J (2009) Insular pest control within a metapopulation context. Biol Conserv 142:1404-1410

Russell JC, Miller SD, Harper GA, MacInnes HE, Wylie MJ, Fewster RM (2010) Survivors or reinvaders? Using genetic assignment to identify invasive pests following eradication. Biol Invasions 12:1747-1757 
Seutin G, White BN, Boag PT (1991) Preservation of avian blood and tissue samples for DNA analyses. Can J Zool 69:82-90

Slatkin M (1993) Isolation by distance in equilibrium and nonequilibrium populations. Evolution 47:264-279

Sokal RR, Rohlf FJ (1981) Biometry: the principles and practice of statistics in biological research. W. H. Freeman, San Francisco

U.S. Fish and Wildlife Service (1987) Endangered and threatened wildlife and plants; determination of endangered and threatened status for two populations of the Roseate Tern. Fed Reg 52:42064-42068

U.S. Fish and Wildlife Service (2010) Virgin Islands tree boa (Epicrates monensis granti) 5-year review: summary and evaluation. USFWS, Southeast Region, Ecological Services, Boquerón

Van Oosterhout C, Hutchinson WF, Wills DPM, Shipley P (2004) MICRO-CHECKER: software for identifying and correcting genotyping errors in microsatellite data. Mol Ecol Notes 4:535-538

Veitch CR, Clout MN (2002) Turning the tide: the eradication of invasive species. IUCN SSC Invasive Species Specialist Group, IUCN, Gland, Switzerland and Cambridge

Weir BS, Cockerham CC (1984) Estimating F-statistics for the analysis of population structure. Evolution 38:1358-1370

Witmer GW, Boyd F, Hillis-Starr Z (2007) The successful eradication of introduced roof rats (Rattus rattus) from Buck Island using diphacinone, followed by an irruption of house mice (Mus musculus). Wildl Res 34:108-115

Witmer GW, Pierce J, Pitt WC (2011) Eradication of invasive rodents on islands of the United States. In: Veitch CR, Clout MN, Towns DR (eds) Island invasives: eradication and management. IUCN, Gland, pp 135-138 